\title{
FOLKLORIC ELEMENTS IN THE NOVEL KOCHARETHI BY NARAYAN
}

\section{SRUTHI. $\mathrm{P}^{1} \&$ GEETHA R. PAI ${ }^{2}$}

${ }^{I}$ MPhil Scholar, Department of English and Languages School of Arts and Sciences, Amrita University, Kochi, India

${ }^{2}$ Assistant Professor, Department of English and Languages School of Arts and Sciences, Amrita University, Kochi, India

Folkloric elements are the effective tool for examining cultural context of Adivasis. This paper focused on folkloric elements in the tribal work Kocharethi, especially its bounds to the cultural context of Tribals in Kerala. It acts as a linking factor and connects people with their own rituals and customs. Postcolonial theory is used in the paper to examine the symptomatic conditions of Tribals, their being, and their preserved indigenous cultural backgrounds. Postcolonial terms like hybridity, cross- culturalism, cultural-identity are the main titles which are analyzed in the paper to examine how folkloric elements being part of Tribal's life. Hybridity refers here to identify mixedness, cultural influences and tries to subvert traditional notion of Tribals. Cross- culturalism compares different cultures and promote various cultures at the time. Cultural- identity is a person's self-perception it related to religion, locality, ethnicity and group and developed the idea that everyone has different cultural identity. The term Tribals used in the paper to make the idea that Tribals are a particular group having their own indigenous cultural heritages.

Kocharethi is a story of Kunjipennu and her family members being in Malayaraya community. It is the first attempt to reconstruct the history Adivasi community with their inevitable folklore and cultural heritage. This paper entitled "Folkloric Elements in the Novel Kocharethi by Narayan" tries to points out how and why Tribals are unique. And scrupulously vents out manners, customs, belief, economic life, folk traditions of Malayaraya community.

KEYWORDS: Adivasi, Cross-Culturalism, Cultural Identity, Hybridity \& Folklore
\end{abstract}

Received: May 16, 2017; Accepted: Jun 16, 2017; Published: Jul 21, 2017; Paper Id.: IJELAUG201717

\section{INTRODUCTION}

The term 'Folklore' is usually used by peasants, or rural groups, or with people from the past. Folklore is a linking factor and it connects people with their rituals and customs. But it is not a matter what linking factor connects them together. It could be a common communication style of language or region where people are involved. But what is the important factor is that a group or particular religion should have some different traditions that it calls its own. Usually, the expected subjects included in folklore are legends, myths, ballads, festivals, folk dance and songs. Each subject provides specific cultures. Those culturally involved backgrounds can be categorized under folklore.

To fully understand what folklore is, it will be helpful to clarify its component parts: the terms like folk and lore. The term folklore was coined by Englishman William Thomas, in 1846. He fabricated the term, for replacing the contemporary expressions of popular antiquities or popular literature. The component term folk and lore is well documented and enriched, through his hands. The concept folk implies to rural, regularly poor and frequently illiterate peasants.

A more modern definition of folk is a particular social group which includes two or more persons, with common traits who expresses their shared identity, through distinctive typical and archetypal traditions. The folklorist 
studies the traditional relics, with folkloric elements of a social group and how they transmitted. Lore proves that, it's easier to define as its meaning has remained relatively stable over the last two centuries. It is the knowledge and traditions of a particular group that has recurrently passed along, by word of mouth.

Folklore includes different genres. They are, Material Culture: It includes folk art, vernacular architecture, textiles and modified mass produced objects. Music: Traditional folk and world music coming under this category of music. Narrative: It means legends, urban legends, fairy tales, folktales and personal experienced narratives. Verbal Art: Jokes, proverbs and world games are included in the category. Beliefs and Religion: Folk religion, ritual and mythology are the main focus of this genre. And last genre Food- Ways: What are the cultural norms coming under this is traditional cooking and customs, the relationship between food and culture. It tries to convey what people think in their own words and actions, what they say or think in folkloric expressions and what they might not be able to in everyday conversation. Folklore is evidently something more than, in other forms of human actions and thoughts.

The meaning of folklore accepts more than a literary reading of a text gives. It requires calls for contextualizing the expression in behavioral and social conditions. Folklore is a form of sublimation. It offers a socially valid outlet for the expression of taboo. It also approves anxiety towards provoking behavior. In a way folklore can be defined as; it is an outlet of effectively conveying a thought. One therefore, need to know the cultural values, taboos, anxieties, customs, rituals and beliefs of the society in which, the individual tradition bearers operate in everyday life. Folklore encapsulates ritual experiences and provides an experience from reality. Folklore is crucial to any knowledge of human experience, with an autobiographical ethnography. It permits a latent view from the inside-out, rather than from the outside- in.

Folklore is an expressive outlet, especially important in making the unconscious -conscious acts. It is a part of belief that has been expressing repression and provides symbols. Folklore is the total result of expressive and sensitive culture, shared by a particular group of people. It amalgamates the traditions and preserving their cultural heritages of the group. The study of folklore has moved from an attitude that, the subjects of folklore are decaying and disappearing to the consideration of them, as efficacious and meaningful part of our present day, of reality. Folklore studies have always focused on interrelations between languages, philosophy, literature and history of particular groups' cultural background, in order to attain keen information about folkloric elements.

This paper makes an attempt to the conventional reading of tribal literature and its folkloric elements. And it tries to put forth the folkloric elements that are being used in this work. From tribal literature, my study concentrates on Kocharethi by Narayan. Kocharethi (1988), the first novel in Malayalam by tribal writer, has depicted real life account of Malayaraya Gothra Community, in Kerala, in the 20th c. The novel goes through the lives of protagonist Kunjippennu, her childhood love, and later about her husband. Cultural traditions, rituals and customs of tribal groups have been richly portrayed, by Narayan.

This paper entitled 'Folkloric Elements in Tribal Literature: A Study of Kocharethi by Narayan', that gives attention to the reading of this book, in postcolonial aspects. Post-colonialism is a concern, which began as early as the renaissance. It involves winning back and reconstituting the native cultures. Postcolonial theory raises the question of race, within colonialism. It makes a sense of oxidant and orient groups. Colonialism is a violent collaboration, where the sense of self-develops through a negotiation, rather than a separation. Here, this paper analyses folkloric elements in the novel Kocharethi, by three terms hybridity, cultural identity and cross- culturalism. 
The notion hybridity inevitably led to a celebration of multiculturalism and plurality. This situation is what Homi Bhabha calls it as 'hybridity'. Hybridity refers to, the state of being two cultures at the border and makes a sense of double consciousness and in-betweens. The migrant is going away to the liminality of identity. Hybridity there is a subversion of being single, unified, purist and notion of identity, in accordance with multicultural positions.

'Cultural Identity' is the feeling of belonging to a group, where a person's self- out set and self-perception is directly connected with nationality, ethnicity, religion, social class, vicinity, generation and locality, or any kind of social group has its own distinct culture. In this way, 'Cultural Identity' can be understood that, it has both the characteristics of individual self and also of the culturally identical members of a group, who shares the same cultural identity and thoughts.

The term 'Cross- Culturalism' is getting prevalent in cultural studies. It is a distinct one and is concerned with the exchange of culture, beyond the boundaries of the nation or cultural groups. Cross- Culturalism in literary and cultural studies believes that, it may be considered as overlapping transnational. The practice of Cross- Culture came out in the era of colonialism and post colonialism, as an ambiguity in their existence. It is usually applied in the situations, involving significant cultural divergence.

This paper tries to clear better than how folkloric elements are highlighted and portrayed in the novel, Kocharethi. My study focuses on customs, traditions and cultural habits of tribal, especially pointing on marriage, pettinukonduvaral (deliver custom), cultivation, indigenous medical treatment and educational system, the effect of modernization and funeral rites of Malayaraya Community. And also points out on how Hybridity, Cross- Culturalism and Cultural Identity being included, as a part of tribal literature.

Tribals of Kerala have never been equated with 'Malayalis.' They are identified as lost or lower sections of the society by terming them as ST, Tribals, of people and so on. Tribals are actually a particular group of people having unique in it. Their lifestyles, languages, folkloric inclined traditions, rituals and customs are significantly different from that of the dominant mainstream. It makes the label strong 'Adivasis, are indigenously separate from other people in any parts of the society.

Narayan's Kocharethi is considered to be the first novel in Malayalam, by an 'Adivasi' writer. Narayan himself is a part of 'Malayaraya' community, so he fulfilled his obligation to his community scrupulously. Here Narayan skillfully vented out realistic depiction of what and who are actually tribes? And he challenges the erroneous representations of the Adivasis in contemporary popular culture.

Tribal life is described in the novel with all folkloric elements like what are their rituals, ceremonies, faiths, institution of marriage and their food, clothing and sheltering habits in accordance with the period prior to the renaissance in Kerala. Narayan tried to keep their attachment with forest, for them forest is not merely a place but it is a place where not only life generating but also life-consuming. He clearly portrayed Tribals' confront with the forces of nature. Anyone in the community knows every change occurs in nature and forest, because nature is a part of their day to day life.

Kocharethi (The Araya Woman) is an excellent account of life and nature of Malayaraya community. In this novel, Kochuraman, Kunjipennu and their family members are considered as Malayarayar(Araya). They inhibit the Western Ghats where they boarded the districts of central Kerala. The novel is growing through the life of its protagonist Kunjipennu. Her childhood love, later life and travails of tribals create history in this novel. Kunjipennu is a daughter of Varikkamakal Ittyadi Arayan, who is an indigenous Ayurveda doctor. Then the novel is crossing through customs and 
traditions exist in Malayaraya tribal clan.

Rituals and customs are inherited in cultural heritage of Tribal groups and are passing from one generation to another. Tribals are encompassed in a unique set of rituals includes birth ceremonies, marriage customs and funeral services are connecting the individual to the society. Social taboos related to the menstruation periods are highly noticeable among them. Each house has an eettappera in which a woman spent seven days during menstruation as well as during childbirth. The Menstruating girl is prohibited to go outside, entering the kitchen and touching anyone.

In Malayaraya tribal community marriages were usually between murapennu and muracherukkan (cousins) and it is regulated by karanavar (elder members in the clan). Kunjipennu's brother Kunjadichan married to his murapennu Paapi. Narayan is a brother to Paapi through blood ties, likes to marry Kunjipennu. But Kunjipennu didn't like the proposal because she is already attracted Kochuraman, famous vaidyan (Ayurveda doctor) in Malayarayar community. When Kunjipennu seemed to hate Narayan Paapi says to her:

Once your father and brother decide to give you in marriage to someone, you'll simply have to go with

That was the custom. If a girl disobeyed, her father or her brother would not hesitate to kick her to

Death; no one would challenge them or blame them for it. (Narayan, 2011).

Exogamy is prohibited in Malayarayar community. Ittyadi, Kunjipennu's father tells her about different illams (clan) among the Malayarayar- Valayillam, Poothaniyillam, Modalakkattillam, Nellippullillam and Chokkayillam. But marriages were permitted only between certain illams (clans). Vala and Nellipulli are related likewise Poothani and Modalakkattuillam related. Modalakkattuillam can marry either from Valayillam or Nellippullillam, and Poothani and Nellippulli can marry from Vala. Fifth clan Chokkayillam is entirely different from those of first four. Chokkayillam is usually considered as outcaste because those who were cast out of their original clan due to commits some terrible crime they become an outcaste.

By birth, Kochuraman belongs to Puliyanmala. When he was the child he had lost his father and mother so he had grown in his chittappanvaidyan, who belongs to Elavungal. That means right now he belongs to Valayillam. Kochuraman didn't have murapennu. So he can marry a girl from in which Kunjipennu belongs to.

Pettinukonduvaral is a ceremony that is attached to pregnancy period of Malayarayar woman. She brought to the home of her aunt and sister in law with a basket of sweetmeats in the seventh month of pregnancy. Delivery is taken place in the eettappera and a vayattati (midwife) assists the role of a nurse. According to the custom of Malayarayar tribe, all the responsibilities of the first childbirth should be done by the girl's family. Up to seven days from the birth of the child- oil bath, eating meat, brought before the deities and performing some rites are considered taboo. Next ceremony is choroonu. It is acted when the child was given rice for the first time. Tobacco, betel leaf and areca nut are the token offered to the midwife. Close acquaintances and relatives present mundu (dhoti) to mother and she is also be served with a sumptuous meal on the seventh day of after delivery when she returned from her bath.

Narayan brilliantly portrayed realistic account of Malaya tribe. They are living on the slopes of a hill which those calls Kollan hill. They are usually cultivating tapioca, pepper, thuvara, pea, yum, kurumbullu, varak plant, wild tubers and etc. The problem they are facing most is the lack of rain. Most probably tribes lost their plow through sieging of wild animals, lack of water and fire. But their cultivation is completely depending on seasonal rain. They are also doing hunting 
and fishing for securing means of food. Malayarayars builds erumaadom to save their agriculture from wild animals. They could realize animals through its sounds, smells and etc. in most days they spend their time in eerumaadom especially at nights to defend from the siege of animals. Their major part of the income coming on the basis of what they have cultivated. Malayarayars were also be cheated through the barter procedure and money dealings. Pepper is one of the sought after and most wanted products among them because of that reason Malayarayars are often be cheated through pepper dealings itself. Their most dealings were with Muslims and Christians traders who often cheated Malayarayars by giving the cheap rate. They had also traded wax and honey, which they obtained from the forest. It indicates that they had a self-sufficient economy in the market.

Malayarayars have their own knowledge about the herbal treatment which is fully centered on nature. Narayan introduces the indigenous knowledge, by Valiyamundan, grandfather of Kunjipennu. He was both mantravadi and velichapadu. But he couldn't save his daughter in law because of her intense fever and fits. Kochuraman is the much more famous people in the generation of the Adivasis with a more sophisticated method of offering medication. Each Araya household had certain family deities. Eldest son of the each family has to do Pooja to the deities. They believe that these Gods will protect them in any bad situation. If they felt any harm these are considered because of God's curse.

KochuPillaAashan is the gentle representative of human-being in the novel. He attempted Adivasis to wean from their primitive way of culture and made an identity through the process of educational enlightenment. He established a school under the name Saraswathi VilasamKalari, which was made of bamboo, its sides was thatched, waist high and the floor had been beaten and smeared with cow dung. Many of them didn't know the meaning of the word Kalari. Aashan tells a story about the origin and place of Arayars in the context of Ramayana and Mahabharatha by mentioning the story of character Arethi. It made clear that Arayars are not ordinary people. Aashan taught them about hygiene, social contact, worship, and he raised Arayars to the world of letters.

Death of Kadutha gives us clear picture of funeral rites among the Malayarayrs. Cooking fires wouldn't be lit in the house where a death had occurred. Kadutha's eldest daughter Kochutti swept out the house in a northerly direction. Kadutha's relatives and children together bathed the corpse and placed it on a plantain leaf in the front of yard near the door with the head facing the east. A wick could be lit and placed near the dead. Friends and relatives spread the pieces of cloth they had brought on the corpse.

According to custom the eldest son has to be performed funeral rites. Eldest son Kochu performed 'vaykari' at first. He took a pinch of rice and placed it to his father's mouth. The eldest male who among the gathered people poured oil into a cupped leaf and put rice and grain in it as accompanying the rites. The children, nephew and nieces, who were observing 'pula' as death related pollution. By chanting incantations, Aadichan placed a chopper on the head of Kochu. Then he dipped a jackfruit leaf and sprinkled the drops all round. A trench of six feet long and six feet deep had been dug in a south-north direction. Kochu rounded the pit thrice by repeating the incantations followed by his uncle Aadichan. The corpse was placed in a southerly direction. The trench was filled with leaves. The son who chanted the mantras and put in three fistfuls of mud; You become, one who was born of the soil, dissolve into the soil and be one with the good of all things. Let your good and evil deeds aid you always' (Narayan, 2011).

After the prayer, everyone engaged to filling up the pit with mud. They would pat it down firmly, placed sticks of murikkin (drumstick plant) and stones all around to keep it away from dogs and foxes. All those who engaged for burial should have to be entered to stream before leaving. Close relatives would have taken part rice gruel together following day. 
'Pula'- the period of isolation was to be enacted for fifteen days. There is some taboo during the period of pula; to touch weapons, they can't enter into cultivated land, perform any rites or appear before idols. Liquor and contact with women are prohibited. On the fifteenth day, a ritual bath and on the sixteenth day, festive meals for relatives also happen.

Krishna Pillai, who was not merely a teacher for them but a good advisor. There is a tremendous change that can be seen after the advent of Aashan. At the next generation, Araya community had got changes in the naming too. They gave Kalyani, Parvathi, Bhavani, Raghavan, Lakshmi etc to their children. The process of globalization and modernization also gave a host of other changes especially living conditions of Malayarayars. Roads cutting across their territory paved the way for all kinds of traders. Narayan describes the conflict of trade between Arayars and outside traders. Often Malayarayars were exploited by the traders. These economic transformations affected by the failure of traditional sources even though they had potential over their traditional customs and rituals.

Narayan is accurately conscious of this clash, between traditional and modern. Christian missionaries came to Malayarayars to convert their religion. For them, Christianity was a shift towards social consequences and the failure of traditional sources of control. It was more potential spiritual power and it offered a sure way to reach heaven. Christianity offered better access to education which enabled them to handle trade and commerce easily. Missionaries helped them to protect their land from the outsider. They furnished Adivasis to handle ancestral cultural heritage. Malayars, after their conversion to Christianity they could not reject their old systems and practices but they preserve it in their mind.

Kocharethi is the first attempt to be reconstructed the history of Adivasi community in Kerala. It is the primal account of the life of the Tribals with their inevitable folklore, cultural heritages. Narayan has heavily drawn Adivasis' tradition. Yes, sure the novel Kocharethi marked a very important point that what position the Tribals had been got in the history of independent India. Narayan not only focused emergence of Adivasi identity but also they are fought with political and higher caste ramifications. Narayan itself is an Adivasi who responded to the crisis being existed in their surroundings. He took this opportunity to be spoken out about their valuable cultural heritages to the public.

Kocharethi by Narayan is a protest writing of source. The author engaged in writing the novel to portray the true lives of the tribal community. Kocharethi, 'The Araya Woman' has the sensibilities of the reader through its potent illustration of Tribal culture and life. This book is about their struggles for land and also challenges to preserve their cultural heritages and customs. Kocharethi by first Malayalam tribal writer and its translator of the book into English would be felt elated at doing something provide visibility to the work that depicted the exact account of sidelined community.

This paper has analyzed some folkloric elements by these keywords like hybridity, cultural- identity and crossculturalism. The main peculiarity of Tribals is, they have a feeling of oneness. They promote their culture whatever obstructs they have. They are proud of their rituals, customs and different cultural heritages. In this novel Kocharethi, Christian missionaries converted Tribals into Christian. It paved the way to get education and standard of living for Tribals. But among the Tribals itself, they preserved their indigenous cultural heredity without allowing to condemn by others. Tribals' identity is equal to these factors like culture, rituals, marriage, funeral and cultivation process. And these folkloric elements are brilliantly portrayed by Narayan.

The Malayarayas were geographically and culturally isolated from the civilized world and who were not allowed free from the outside authority. During the 19th c, there were several changes seem to have affected them. Even though 
tribals are following a culture they have a sense of double consciousness in between them due to modernization, globalization and advent of Christian missionaries. This hybrid culture directly affected to education, their way of live, dressing and food habits. But noted point is that they accepted only of those cultures which were suitable to them. The consequence of modernization introduced Travancore government and British colonial rulers. Large quantities of teaks were used for shipbuilding, railways and spices were used to export other countries. These changes led in the mode of cultivation too.

Kocharethi, the tribal novel says directly about folklores of Tribals. It can be considered as a good record of tribal culture and folklore. Parvati and Padmanabhan are depicted as ideals of a later generation. They are educationally qualified, have a good job and staying in the city. They got married by against clan's custom. It doesn't mean that they are fully devoid of their rich culture but a conspicuous example of cross - culturalism. Later generations depicted in the novel are accepting outside culture. Cross - culturalism believes in overlapping to other culture. Monocropping had been introduced over great areas of land obtained by evicting the Adivasis, led to depletion of the rich biodiversity. Lying of the railway, other transportation and concept of building etc are affected their traditional way of living.

\section{CONCLUSIONS}

Naming as 'Adivasi' has its own importance in historical, political, social and cultural backgrounds of Tribals. In India, Tribals are generally considered to be 'Adivasi,' literally; it is meant indigenous or original inhabitants. All tribal communities are not alike; they are witnesses of different social and historical background. Adivasis are the best perceived as humans to be kept in isolation. They are living in remote and backward regions. Consequently, popular perspective on tribals/ Adivasis is merely their isolation in the forest and their indigenous culture and practices. Kocharethi is a novel about particular clan 'Malayaraya' which belongs to the tribal community. They too have their tribal dialect, animism, primitive occupation, nomadic habits, love, drink, song and dance. Tribals are casteless, classless and none of them have rational discrimination. They are keeping egalitarianism in nature.

\section{REFERENCES}

1. Anderson, Benedict. (1991). Imagined Communities: Reflections on the Origin and Spread of Nationalism. London: Versos.

2. Bhabha, Homi K. (2004). The Location of Culture. London: Routledge.

3. Bronner, Simon J., ed. (2007). The Meaning of Folklore: The Analytical Essays of Alan Dudes. Logan, UT: Utah State University Press.

4. Gellner, E. (2006. Nations and Nationalism. Oxford: Blackwell.

5. Narayan. (2011). Kocharethi. (Catherine Thankamma, Trans.). New Delhi: Oxford University Press. (Original work published 1988).

6. Parry, B. (2004). Postcolonial Studies: A Materialist Critique. London: Routledge.

7. Propp, Vladimir. (1968). Morphology of the Folktale. Austin: University of Texas Press.

8. Trimmer, Joseph and Tilly Warnock. (1992). Understanding Others: Cultural and Cross-Cultural Studies and the Teaching of Literature. Urbana, 111: National Council Teachers of English. 
